\title{
Comparison of Pethidine and Dexmedetomidine for the Control of Intraoperative Shivering Under Spinal Anesthesia
}

\author{
Viral Prakashkumar Patel ${ }^{1}$, Shital Hardik Halvadia ${ }^{1}$ \\ ${ }^{1}$ Assistant Professor, Department of Anesthesia, GMERS Medical College, Gandhinagar, Gujarat, India.
}

\section{Abstract}

Background: Spinal anesthesia significantly impairs the thermoregulation system by inhibiting tonic vasoconstriction, which plays a significant role in temperature regulation. Various non-pharmacological and pharmacological methods are available for the control of shivering during anesthesia. The present study was done with an aim to compare the two drugs Pethidine and Dexmedetomidine for the control of intraoperative shivering under spinal anesthesia. Subjects and Methods: A prospective randomized study was carried out in the Department of Anaesthesiology, on 100 patients who developed intra-operative shivering following spinal anesthesia for numerous surgical procedures. When patients developed shivering of higher than mentioned grades, they were randomly assigned to one of the 2 study groups: Group DDexmedetomidine group receiving single intravenous bolus dose of $0.5 \mathrm{mcg} / \mathrm{kg}$ over $5 \mathrm{~min}$. Group P: Pethidine group patients receiving $0.5 \mathrm{mg} / \mathrm{kg}$ Pethidine IV over $5 \mathrm{~min}$. Patients were intently monitored for the failure of the drug, Recurrence of shivering and side effects like nausea, vomiting, bradycardia $(<50 / \mathrm{min})$, hypotension ( $>20 \%$ of baseline), giddiness and sedation score were recorded. Results: We found the Pethidine group had $62.5 \%$ and Dexmedetomidine had $67.5 \%$ of grade 3 shivering. The grades of shivering were comparable between the two groups with no statistical difference. We found the dexmedetomidine group had a significant reduction in time required to control shivering and vanishing of shivering after drug. Conclusion: Both dexmedetomidine $(0.5 \mathrm{mcg} / \mathrm{kg})$ and Pethidine $(0.5 \mathrm{mg} / \mathrm{kg})$ are effective in treating patients with post-spinal anesthesia shivering but the time taken for control of shivering was shorter with Dexmedetomidine as compared to Pethidine.

Keywords: Dexmedetomidine, Pethidine, Shivering, Spinal anesthesia.

Corresponding Author: Dr. Shital Hardik Halvadia, Department of Anesthesia, GMERS Medical College, Gandhinagar, Gujarat, India. Email: researchguide86@gmail.com

Received: April 2020

Accepted: April 2020

\section{Introduction}

Shivering is defined as an involuntary, repetitive activity of skeletal muscles. The mechanisms of shivering in patients undergoing surgery are mainly intraoperative heat loss, increased sympathetic tone, pain, and systemic release of pyrogens. $^{[1]}$

Shivering besides being physiologically stressful to the patient also causes unpleasant to the anesthesiologists and surgeons. Shivering can occur in patients receiving regional anesthesia as well as those patients recovering from general anesthesia. It causes several undesirable physiologic consequences, including an increase in oxygen consumption, hypercarbia and an increase in minute ventilation. It induces arterial hypoxemia, lactic acidosis, increased intraocular pressure, intracranial pressure and interference with patient monitoring. ${ }^{[2]}$ Shivering may negate orthopedic procedures like fractures and dislocations and may also cause damage to the dental prosthesis. ${ }^{[3]}$

Spinal anesthesia significantly impairs the thermoregulation system by inhibiting tonic vasoconstriction, which plays a significant role in temperature regulation. ${ }^{[4]}$ Spinal anesthesia also causes a redistribution of core heat from the trunk (below the block level) to the peripheral tissues. These two effects predispose patients to hypothermia and shivering. ${ }^{[5]}$ The median incidence of shivering related to regional anesthesia observed in a review of 21 studies is $55 \% .1$ Shivering increases oxygen consumption, lactic acidosis, carbon dioxide production, and metabolic rate by up to $400 \%$. $^{[6,7]}$ Therefore, shivering may cause problems in patients with low cardiac and pulmonary reserves. The best way to avoid these intraoperative and postoperative shivering-induced increases in hemodynamic and metabolic demands is to prevent shivering in the first place. ${ }^{[1]}$

Various non-pharmacological and pharmacological methods are available for the control of shivering during anesthesia. Fluid warmers, ambient operation theater temperature, space blankets, ${ }^{[8]}$ surgical drapes and active circulating water mattress are some of the non-pharmacological methods. Pharmacological methods using various drugs like Tramadol Clonidine, Doxapram, Dexmedetomidine, Pethidine, Nefopam, Neostigmine, Magnesium sulfate have been tried. ${ }^{[8-10]}$ Although Dexmedetomidine is among several pharmacological agents used for the treatment of shivering, its effects on prevention of shivering during central neuraxial blockade have not been evaluated to date. Dexmedetomidine is a highly selective $\alpha 2$-adrenoceptor agonist with potent 
effects on the central nervous system..$^{[1-13]}$ In the pursue a lot of safe and efficacious drugs, we tend to compared 2 effective and safe drugs Dexmedetomidine and Pethidine, intravenously administered for treating shivering in patients who received spinal anesthesia for numerous surgical procedures. Hence the present study was done with an aim to compare the two drugs Pethidine and Dexmedetomidine for the control of intraoperative shivering under spinal anesthesia.

\section{Subjects and Methods}

A prospective randomized study was carried out in the Department of Anaesthesiology, on patients who developed intra-operative shivering following spinal anesthesia for numerous surgical procedures.

Patients of either gender aged between 20-60 years, ASA grade of I -II and patients who develop shivering of grade 23 (Crossley and Mahajan scale) following spinal anesthesia were enclosed within the study once getting informed consent. Patients with fever, drug allergic reaction, thyroid illness and neuromuscular diseases, Surgery lasting quite four hours, Patients who develop shivering even before administering spinal anesthesia, Patients requiring supplementation with general anesthesia were excluded from the study. All patients who were included in the study were pre-medicated with tablet Diazepam 10mg on the night before the surgery and tablet Diazepam 5mg on the morning of the surgery, administered orally with sips of water two hours prior to the planned surgery. They were preloaded with $500 \mathrm{ml}$ of Ringers Lactate solution. Patients were taken into the operation theatre and baseline parameters were recorded using monitors. Baseline temperature was recorded, employing a thermometer in the axilla placed in the vicinity of the axillary artery. Operation theatre temperature was kept at 22-25C. All patients in our study received spinal anesthesia in left lateral position using $25 \mathrm{G}$ Quincke needles by means of midline approach within the L3-L4 intervertebral space under strict sterile precautions and local anesthesia to the skin. Following the free flow of CSF, $0.5 \%$ Bupivacaine (hyperbaric) was injected, counting on the need for surgery (3-4ml). Patients were administered 5 liters of oxygen by Hudson mask and were adequately covered with sterile surgical drapes.

Shivering of grades 2 and 3 as proposed by Crossley and Mahajan Scale of Shivering, was considered to need treatment. When patients developed shivering of higher than mentioned grades, they were randomly assigned to one of the 2 study groups -

Group D- Dexmedetomidine group receiving a single intravenous bolus dose of $0.5 \mathrm{mcg} / \mathrm{kg}$ over $5 \mathrm{~min}$.

Group $\mathbf{P}_{-}$Pethidine group patients receiving $0.5 \mathrm{mg} / \mathrm{kg}$ Pethidine IV over $5 \mathrm{~min}$.

The study drug was then administered intravenously as per the assigned group. The time from drug administration until the disappearance of shivering was accurately noted in seconds. Patients were monitored at intervals of 1 minute, $3 \mathrm{~min}, 5 \mathrm{~min}$ and thenceforth 10, 20 and 30 minutes until the end of surgery. Patients were intently monitored for the failure of the drug, Recurrence of shivering and side effects like nausea, vomiting, bradycardia $(<50 / \mathrm{min})$, hypotension $(>20 \%$ of baseline), giddiness and sedation score were recorded. The sedation score was evaluated with a four-point scale as per Filos.

Bradycardia, hypotension was treated with Atropine and Mephentermine, respectively and vomiting with Metoclopramide in titrated doses when required.

\section{Grade of Shivering}

Crossley and Mahajan Scale, Temperature at the beginning of shivering, Time from drug administration to control of shivering, vanishing of shivering on treatment, Recurrence of shivering after drug administration, any hemodynamic changes, adverse effects of drugs were recorded.

\section{Statistical analysis:}

The recorded data was compiled and entered in a spreadsheet computer program (Microsoft Excel 2007) and then exported to the data editor page of SPSS version 15 (SPSS Inc., Chicago, Illinois, USA). Descriptive statistics included computation of percentages, means and standard deviations. The statistical tests applied for the analysis were Pearson's chi-square test $(\chi 2)$, t-test, and One-way Analysis of Variance. For all tests, confidence level and level of significance were set at $95 \%$ and $5 \%$, respectively.

\section{Results}

Table 1: Comparison of a range of variables between Pethidine and Dexmedatomedine group

\begin{tabular}{|c|c|c|c|}
\hline Variables & $\begin{array}{l}\text { Group } \\
\mathbf{P}(\mathbf{n}=50) \%\end{array}$ & $\begin{array}{l}\text { Group } \\
\text { D(n=50) \% }\end{array}$ & P-value \\
\hline \multicolumn{4}{|l|}{ Gender } \\
\hline Male & $30(60)$ & $27(54)$ & \multirow[t]{2}{*}{$0.01 *$} \\
\hline Female & $20(4)$ & $23(46)$ & \\
\hline Age & $40.2(10.6)$ & $42.1(10.9)$ & 0.22 \\
\hline \multicolumn{4}{|l|}{ Temperature } \\
\hline Pre Operative & $37.4(0.5)$ & $37.3(0.4)$ & 0.1 \\
\hline During shivering & $36.5(0.5)$ & $36.4(0.4)$ & 0.09 \\
\hline \multicolumn{4}{|l|}{ Grade of Shivering } \\
\hline Grade 1 & $0(0)$ & $0(0)$ & \multirow{3}{*}{0.11} \\
\hline Grade 2 & 19(38) & $16(32)$ & \\
\hline Grade 3 & $31(62)$ & $34(68)$ & \\
\hline \multicolumn{4}{|l|}{ Heart rate } \\
\hline During shivering & $84.5(13.2)$ & $80.1(5.1)$ & $0.03^{*}$ \\
\hline $\begin{array}{l}\text { After control of } \\
\text { shivering }\end{array}$ & $83.2(10.4)$ & $72.9(6.5)$ & $0.01^{*}$ \\
\hline $\begin{array}{l}\text { Time required to } \\
\text { control shivering } \\
\text { after drug }\end{array}$ & $412(15.9)$ & $206.4(18.9)$ & $0.002^{*}$ \\
\hline $\begin{array}{l}\text { Disappearance of } \\
\text { shivering (in } \\
\text { seconds) }\end{array}$ & $514.2(9.8)$ & $299.4(8.7)$ & $0.03^{*}$ \\
\hline \multicolumn{4}{|c|}{ Post drug complication } \\
\hline Recurrence & $8(16)$ & $2(4)$ & $0.03^{*}$ \\
\hline Nausea & $7(14)$ & $0(0)$ & $0.04^{*}$ \\
\hline
\end{tabular}

$*$ indicates statistically significance at $\mathrm{p}<0.05$

During the study period, 100 patients (50 in the pethidine group and 50 in Dexmedetomidine) were included into the study. All variables of both groups (group P and group D) are shown in [Table 1]. The mean age of the study population was $41.2 \pm 5.4$ years. Fifty-seven $(57 \%)$ were men. We found Pethidine group had $62.5 \%$ and Dexmedetomidine had $67.5 \%$ of grade 3 shivering. The grades of shivering were comparable between the two groups with no statistical 
difference. We found the dexmedetomidine group had a significant reduction in time required to control shivering and vanishing of shivering after drug. Recurrence of shivering was more with the pethidine group and it is statistically significant. Incidence of nausea was noted in group $\mathrm{P}$ where Pethidine was used as an anti-shivering agent and it is also statistically significant.

\section{Discussion}

Spinal anesthesia is a safe and popular technique of anesthesia used in different surgeries worldwide. Spinal anesthesia is a type of central neuraxial blockade, with Epidural anesthesia being the other commonly used technique. However, SA is not a complication-free technique; shivering is a common complication of SA, with an incidence of $40-60 \%$ in patients who undergo SA. ${ }^{[14]}$ Though shivering is a protective mechanism to preserve body heat, it causes patient discomfort and pain and maybe dangerous in patients with impaired cardiovascular reserves or limited respiratory capacity, as shivering increases the circulating catecholamine, HR, cardiac output, minute ventilation, oxygen consumption, metabolic $\mathrm{CO} 2$ production and lactic acid level. It also increases intraocular and intracranial pressure and postoperative pain due to surgical incision stretching. Shivering may also interfere with the monitoring of patients by causing artifacts on the ECG or disrupting BP and pulse oximetry readings. ${ }^{[15]}$ Additionally, shivering in patients with ASA grades III and IV may cause challenges for the surgeon and increase the operative time.

Hypothermia is a major risk for shivering, but there is no definite linear relationship between body temperature and the occurrence of shivering. Other major risk factors include age, sensory block level, the temperature of the operating room and temperatures of the IV solutions. ${ }^{[16]}$

The exact mechanisms to explain the occurrence of shivering during SA have not yet been elucidated. Possible mechanisms include central thermoregulation disturbance, internal body heat redistribution, and body heat loss to the environment. ${ }^{[17]}$ Regional and general anesthesia are known to impair the efficiency of the hypothalamic thermoregulatory centre, causing different grades of hypothermia. ${ }^{[18]}$ Under regional anesthesia, vasodilatation and redistribution of the core temperature are restricted to the lower body below the block, while vasoconstriction and shivering are restricted to the upper body, as they are inhibited below the level of the block due to sympathetic and somatic nerve blocks. ${ }^{[19]}$

The effectiveness of Pethidine in treating postoperative shivering is difficult to find an adequate explanation. It has been reported to be effective in treating amphotericin B related shaking chills and infusions of granulocytes and plat elets. A randomized trial was conducted by Mahesh T, Lavanya $\mathrm{K}$ on 40 patients of ASA I and II status to compare the effectiveness of Pethidine and tramadol in controlling shivering after neuraxial block. ${ }^{[20]}$ This study revealed that tramadol reduced the occurrence of postanesthetic shivering more significantly than Pethidine. Whereas in our study we compared Dexmedetomidine versus Pethidine and found Dexmedetomidine to be more effective.

Rajagopalan venkataraman et al conducted a prospective, randomized, double-blind control study on 90 patients who developed shivering under spinal anesthesia. ${ }^{[21]}$ they were randomly allocated into three groups each containing 30 patients. The drugs compared were tramadol $1 \mathrm{mg} / \mathrm{kg}$ given to one group, clonidine $1 \mathrm{mcg} / \mathrm{kg}$ received by one group and dexmedetomidine $0.5 \mathrm{mcg} / \mathrm{kg}$ received by the last group. They concluded that Dexmedetomidine is better than tramadol and clonidine in the control of shivering because of its faster onset and less recurrence rate.

Our present study also found Dexmedetomidine to be more effective in controlling shivering than opioid Pethidine. Zahedi. $\mathrm{H}$ in their study comparing effect of tramadol and Pethidine for post anaesthetic shivering revealed tramadol to be more superior to Pethidine as it induced a faster termination of post anaesthetic shivering under spinal anesthesia. ${ }^{[22]}$ Claybon and Hirch reported after general anesthesia that in 73 percent of patients, pethidine $25 \mathrm{mg}$ arrested shivering within 5 minutes after general anesthesia. Later, Pethidine was shown to be superior to both morphine and fentanyl in this respect.

A more recent study shows that 11 out of 14 patients stopped shivering within 5 minutes after pethidine $25 \mathrm{mg}$ i.v. and that Pethidine was effective in reducing the increased metabolic demand of shivering. In demonstrating the effectiveness of Pethidine, our results agree with these studies and suggest that Pethidine may be marginally superior to doxapram in this regard. ${ }^{[23]}$

Following spinal anesthesia, our study had a mean temperature of 36.5C for group Dexmedetomidine and 36.4 for group Pethidine at which shivering occurred. This result was in line with the study of Aditi Dhimar and his associates. ${ }^{[24]}$

In our study, shivering was controlled in patients in the Pethidine group in $412 \pm 15.9$ seconds after drug administration, while in patients in the Dexmedetomidine group it was $206.4 \pm 18.9$ seconds. The results between the two groups were statistically significant, with P-value $(0.00)$. This result was likely with Aditi Dhimar's study and associates for intraoperative and postoperative shivering control; complete shivering disappearance occurred in 5 minutes in the Tramadol group compared with the Pethidine group where it took 20 minutes comparable to our study. In a study by Geeta Mittal, et al, Shivering control was $2.52 \pm 0.44$ in the Dexmedetomidine group and $5.92 \pm 0.81$ in the Tramadol group, which was comparable to our group. 25 Dexmedetomidine displays specific and selective $\alpha 2$ adrenoceptor agonist in the brain and spinal cord. The responses to the activation of these receptors include decreased sympathetic tone with attenuation of the neuroendocrine and hemodynamic responses to anesthesia and surgery. Thus, Dexmedetomidine can mediate both the beneficial and unwanted effects of shivering provoked by hypothermia, such as increased catecholamine concentrations, oxygen consumption, blood pressure, and heart rates. ${ }^{[17,26]}$ In our study, the incidence of nausea and vomiting with Dexmedetomidine was $0 \%$. The results match that of Sukhminder Jit Singh Bajwa et al's other studies. ${ }^{[16]}$

In our study, the rate of Recurrence of shivering in Pethidine was $16 \%$ compared to $4 \%$ in the Dexmedetomidine group which is comparable to Aditi A. Dhimar et al. ${ }^{[24]}$ reported a similar more recurrence rate with Pethidine as in our study 
$(50 \%)$ but the dose used in their study was $1 \mathrm{mcg} / \mathrm{kg}$.

The limitation to this study was that we did not estimate the mean volumes of the irrigating fluids in each group. We recommend conducting further studies on both drugs with increased sample sizes and different doses.

\section{Conclusion}

Both dexmedetomidine $(0.5 \mathrm{mcg} / \mathrm{kg})$ and pethidine $(0.5 \mathrm{mg} / \mathrm{kg})$ are effective in treating patients with post-spinal anesthesia shivering but time taken for control of shivering was shorter with dexmedetomidine as compared to Pethidine. Dexmedetomidine causes lesser side effects as compared to Pethidine, arousable sedation caused by dexmedetomidine provides additional comfort to the patient.

\section{References}

1. Crowley LJ, Buggy DJ. Shivering and neuraxial anesthesia. Reg Anesth Pain Med. 2008;33:241-52.

2. Buggy DJ, Crossley AW. Thermoregulation, mild perioperative hypothermia and postanaesthetic shivering. $\mathrm{Br} \mathrm{J}$ Anaesth 2000;84(5):615-28.

3. Predictors of Hypothermia during Spinal Anesthesia | Anesthesiology | ASA Publications [Internet]. [cited $2019 \mathrm{Feb}$ 11]. Available from: http://anesthesiology.pubs.asahq.org/article.aspx?articleid=1945666.

4. Glosten B, Sessler DI, Faure EA, Karl L, Thisted RA. Central temperature changes are poorly perceived during epidural anesthesia. Anesthesiology. 1992;77:10-6.

5. Ozaki M, Kurz A, Sessler DI, Lenhardt R, Schroeder M, Moayeri A, Noyes KM, Rotheneder E. Thermoregulatory thresholds during epidural and spinal anesthesia. Anesthesiology. 1994;8:282-8.

6. Tsai YC, Chu KS. A comparison of tramadol, amitriptyline, and meperidine for postepidural anesthetic shivering in parturients. Anesth Analg. 2001;93:1288-92.

7. Macintyre PE, Pavlin EG, Dwersteg JF. Effect of meperidine on oxygen consumption, carbon dioxide production, and respiratory gas exchange in postanesthesia shivering. Anesth Analg. 1987;66:751.

8. Camus Y, Delva E, Cohen S, Lienhart A. The effects of warming intravenous fluids on intraoperative hypothermia and postoperative shivering during prolonged abdominal surgery. Acta Anaesthesiol Scand 1996;40(7):779-82.

9. Buggy D, Hughes N. Pre-emptive use of the space blanket reduces shivering after general anesthesia. Br J Anaesth 1994;72(4):393-6.

10. Tsai YC, Chu KS. A comparison of tramadol, amitriptyline, and meperidine for postepidural anesthetic shivering in parturients. Anesth
Analg 2001;93(5):1288-92.

11. Doze VA, Chen BX, Maze M. Dexmedetomidine produces a hypnoticanesthetic action in rats via activation of central alpha-2 adrenoceptors. Anesthesiology. 1989;71:75-9.

12. Virtanen R, Savola JM, Saano V, Nyman L. Characterization of the selectivity, specificity and potency of medetomidine as an alpha-2 adrenoceptor agonist. Eur J Pharmacol. 1988;150:9-14.

13. Elvan EG, Oç B, Uzun S, Karabulut E, Coşkun F, Aypar U. Dexmedetomidine and postoperative shivering in patients undergoing elective abdominal hysterectomy. Eur J Anaesthesiol. 2008;255:357-64.

14. Moawad HES, Elawdy MM. Efficacy of intrathecal Dexmedetomidine in prevention of shivering in patients undergoing transurethral prostatectomy: a randomized controlled trial. Egypt J Anaesth 2015;31(2):178-81.

15. De Witte J, Sessler DI. Perioperative shivering: physiology and pharmacology. Anesthesiology. 2002;96(2):467-84.

16. Bajwa SJ, Gupta S, Kaur J, Singh A, Parmar S. Reduction in the incidence of shivering with perioperative Dexmedetomidine. A randomized prospective study. J Anesthesiol Clin Pharmacol. 2012;28:86-91.

17. Kurz A, Sessler I, Schroeder M, Kurz M. Thermoregulatory response thresholds during spinal anesthesia. Anesth Analg. 1993;77:721-6.

18. Joris J, Ozaki N, Sessler D, et al. Epidural anesthesia impairs both central and peripheral thermoregulatory control during general anesthesia. Anesthesiol. 1994;80:268-77.

19. Berti M, Fanelli G, Casati A, et al. Hypothermia prevention and treatment. Anesthesia. 1998;53(2):46-7.

20. Mahesh T, Karthik L. A randomised trial comparing efficacy, onset and duration of action of Pethidine and tramadol in abolition of shivering in the intraoperative period. J Clin Diagnostic Res JCDR 2014;8(11):GC07

21. Venkataraman R, Karthik K, Pushpharani A, Mahalakshmi A. A prospective, randomized, double blinded control study on comparison of tramadol, clonidine and dexmeditomidine for post spinal anesthesia shivering. Rev Brasileira de Anestesiologia 2018;68(1):42-8.

22. Zahedi H. comparison of tramadol and Pethidine for post anaesthetic shivering in elective cataract surgery. J Res Med Sci 2004;9(5):235-9.

23. Double-blind comparison between doxapram and Pethidine in the treatment of postanaesthetic shivering. - PubMed - NCBI [Internet]. [cited 2019 Feb 14]. Available from: https://www.ncbi.nlm.nih.gov/pubmed/8251281

24. Dhimar AA, Patel MG, Swadia V N. Tramadol for control of shivering (Comparison with Pethidine) Indian J Anaesth 2007;51(1):28-31.

25. Mittal G, Gupta K, Katyal S, Kaushal S. Randomised double-blind comparative study of Dexmedetomidine and tramadol for post-spinal anesthesia shivering. Indian J Anaesth 2014;58(3): 257-262.

26. Frank SM, Higgins MS, Breslow MJ, Fleisher LA, Gorman RB, Sitzmann JV, et al. The catecholamine,cortisol, and hemodynamic responses to mild perioperative hypothermia. Anesthesiology. 1995;82:83-93.

Copyright: () the author(s), 2020. It is an open-access article distributed under the terms of the Creative Commons Attribution License (CC BY 4.0), which permits authors to retain ownership of the copyright for their content, and allow anyone to download, reuse, reprint, modify, distribute and/or copy the content as long as the original authors and source are cited.

How to cite this article: Patel VP, Halvadia SH. Comparison of Pethidine and Dexmedetomidine for the Control of Intraoperative Shivering Under Spinal Anesthesia. Acad. Anesthesiol. Int. 2020;5(1):96-99.

DOI: dx.doi.org/10.21276/aan.2020.5.1.19

Source of Support: Nil, Conflict of Interest: None declared. 